\title{
Comparative study on aerated concrete using steam curing and conventional curing method
}

\author{
Rohith Naidu T Y*, G.V.V Satyanarayana ${ }^{l}$ \\ * PG student, Civil Engineering Department, GRIET, Hyderabad, India. \\ ${ }^{1}$ Professor, Civil Engineering Department, GRIET, Hyderabad, India.
}

\begin{abstract}
Aerated concrete is made by introducing gas into concrete, the number dependent upon the necessities for strength. One methodology to attain this can be by utilizing Al Powder that reacts with the lime made upon association of the cement. The aim of the present study was to research the comparison between the steam curing method and the conventional curing method. The results specified that a rise in powdered aluminium content caused a decrease within the compressive strength, and an increase in change in volume when the aluminium powder is increased.

Keywords: Aerated Concrete, Aluminium powder, Conventional curing, Aerated concrete, Change in volume.
\end{abstract}

\section{Introduction}

Bricks stay one of the foremost necessary building materials within the country. Brick creating may be an ancient trade in an Asian nation, usually confined to rural areas. it's directly or indirectly caused a series of environmental and health issues. At a neighbourhood level, within the neck of the woods of a brick oven, environmental pollution from brickmaking operations is injurious to human health, animals, and flora. The environmental pollution from brickmaking operations contributes to the phenomena of world warming and global climate change. Extreme weather might cause degradation of the brick surface thanks to frost injury. various sorts of blocks will be used as another to the red bricks, to scale back environmental pollution and heating. Aerated Concrete blocks are also one of the solutions for brick replacement. Aerated Concrete is one of all the eco-friendly products.

There are many typical conventional ways for hardening concrete, although the most effective choice can rely upon numerous factors, like water availableness, hardening materials, labour constraints and climatic conditions. The method used in this study was by keeping the aerated concrete in room temperature for 28 days.

\subsection{Objective}

To investigate the comparison study of aerated concrete using steam curing method and conventional curing method. To study the conventional curing method of the aerated concrete of optimum dosage of powdered aluminium. To investigate the influence of the conventional curing method on the compressive strength of aerated concrete. To execute the volumetric analysis of the aerated concrete using conventional curing method.

\section{Literature Survey}

Kaliprasanna sethy (2018), this paper contains data concerning aluminium powder impact on compressive strength and density of autoclave aerated concrete blocks. It conjointly contains aluminium powder that has directly affected the bubble diameter of the AAC block.[1]

Prajakta Dinesh Bulkade (2017) investigated the analysis of building with conventional bricks and aerated concrete blocks with silicon admixture, In most of the cases Autoclaved aerated Concrete block is stronger than a standard brick manufactured from clay and each of them have their pros and cons. oven Burnt Brick is majorly used exterior wall material within the market. Also, Aerated Concrete (AAC) could be a non flammable, cementitious building material that's increasing into new worldwide markets. Here we tend to aimed to match the environmental impact of materials 
oven Burnt Brick and Autoclaved Aerated Concrete used for wall assemblies. The final objective is to judge the materials on the bases of Life Cycle Assessment.[2]

Satish Kumar B (2017), Concluded that the usage of $\mathrm{AC}$ blocks reduces the price of construction up to $20 \%$ as a reduction of loading of wall on beam. the employment of AC block additionally reduces the need for materials up to $50 \%$. Aerated concrete will manufacture a light-weight weight, environmentally friendly, lower constant of thermal growth, mold resistance, reduced dead weight, and sensible sound insulation as a result of air voids within aerated concrete.[3]

Anurag Wahane (2016), He Achieved that The delicate weight belongings of the AAC block effects into higher stability of the AAC blocks within the form of the homes. because the impact of the earthquake is instantly distributed proportionally to the load of the building. The building-designed exploitation AAC blocks are a lot dependable and safer. AAC blocks are amazingly advanced in terms of strength. A higher level of power of these blocks offers higher balance to the structure of the building. $\mathrm{AAC}$ is factory-made from non-perishable substances, maintaining interiors sleek and durable.[4]

Farhana M. Sayed et al. (2014) studied on aerated concrete blocks novel material for construction, $\mathrm{AAC}$ is one in all the materials which might cope up with the shortage of building raw materials and may manufacture a light-weight, energy economical and environmentally friendly concrete. This study deals with the introduction to the method of the autoclaved aerated concrete and its benefits compared to the conventional concrete.[5]

George Schober (2005), AAC with its multihierarchical pore structure defines essential properties of AAC, comparatively high strength and the low thermal physical phenomenon is extraordinary in some aspects, the pore sizes vary from nanometre to millimetre scale and also the most relevant size ranges lie at the lower and higher finish of the distribution.

\section{Methodology}

\subsection{Materials used}
a. Ordinary Portland Cement (OPC)
b. Fly ash
c. Lime stone powder
d. Quarry dust
e. GGBS

\author{
f. Water \\ g. Aluminium Powder \\ h. Sand
}

\subsection{Mix Proportion}

Totally 3 Proportions were designed in this study, as this concrete is an expansion concrete the proportions were designed by the above literature survey.

In the first proportion the sand was taken twice the cement and water cement ratio was 0.5 along with 3 different aluminium content and also super plasticizer was used to reduce the water content.

In the Second Proportion the sand was totally replaced with limestone powder and quarry dust to increase the density of the concrete and volume. In the third proportion fly ash and GGBS was added additionally for the $2^{\text {nd }}$ proportion to check for the density and change in volume.

\subsection{Conventional Curing method}

The Cubes were casted for three different types of proportions with three different types of aluminium dosage. As we know that there are several conventional curing methods for concrete we are using water curing method in this study

The cubes were casted and cured in water for 28 days where as when it comes to steam curing the cubes were casted and cured in steam curing tank for just 3 hours in $100 \pm 5^{\circ} \mathrm{C}$ to gain the early strength of the concrete as per the procedure.

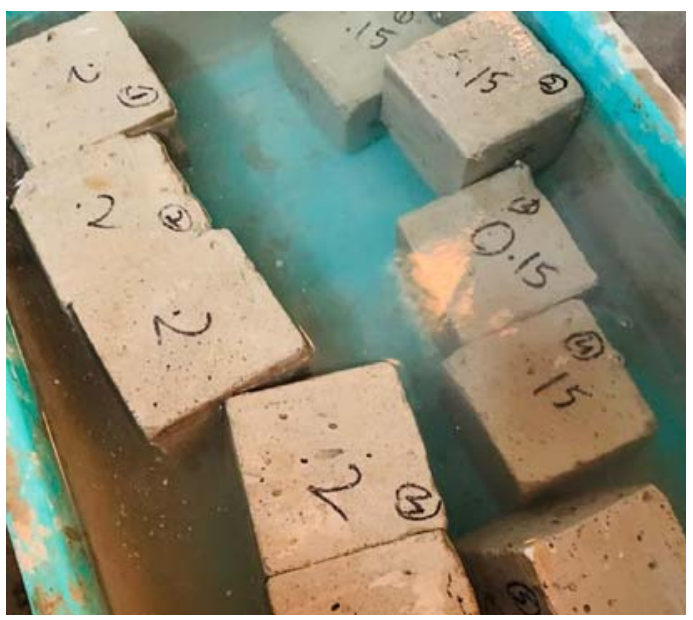

Fig 1. Water curing was done for Concrete Blocks

\subsection{Steam Curing Method}

Steam curing is done to gain the early strength of a concrete as per the procedure. In this study we are 
comparing the steam curing with the conventional curing method that is water curing method.

Accelerated hardening is helpful within the manufacturing trade whereby high early-age strength allows the removal of the formwork among twenty-four hours thereby reducing the cycle time leads to price-saving advantages. The most normally adopted hardening techniques area steam hardening at gas pressure, heat water hardening, boiling water hardening, and autoclaving.

\subsection{Volumetric Analysis}

We know that aerated concrete is an expansion concrete due to the addition of the aluminium powder, the change in volume was found in this study.

After pouring the slurry concrete into the mold the initial height was taken, after 24 hours once the concrete gets harden the final height is recorded and the change in volume is calculated.

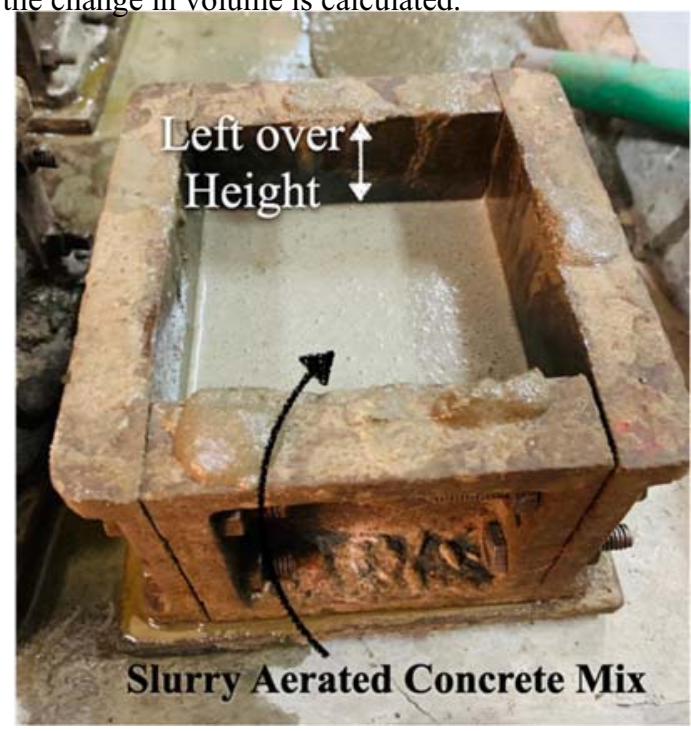

Fig 2. Left over Height of the concrete

To find the initial height of the concrete, we can find by subtracting the total height of mold to the left over height .

The final height of the concrete can be find by adding the total height of the mold and the height of the expanded concrete.

The change in volume of the concrete can be calculated by the below formula.

$$
\begin{gathered}
\text { Final Height of the concrete - } \\
=\frac{\text { Initial Height of the concrete }}{\text { Initial height of the concrete }} \\
* 100
\end{gathered}
$$

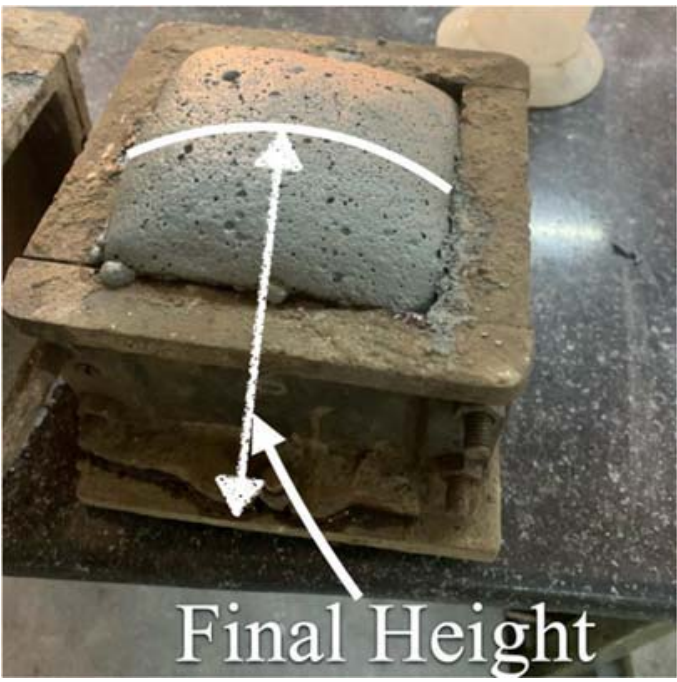

Fig 3. Final Height of the concrete

\section{Results}

4.1 Compressive Strength of Aerated Concrete for optimum dosage of Aluminium Content for Proportion 2

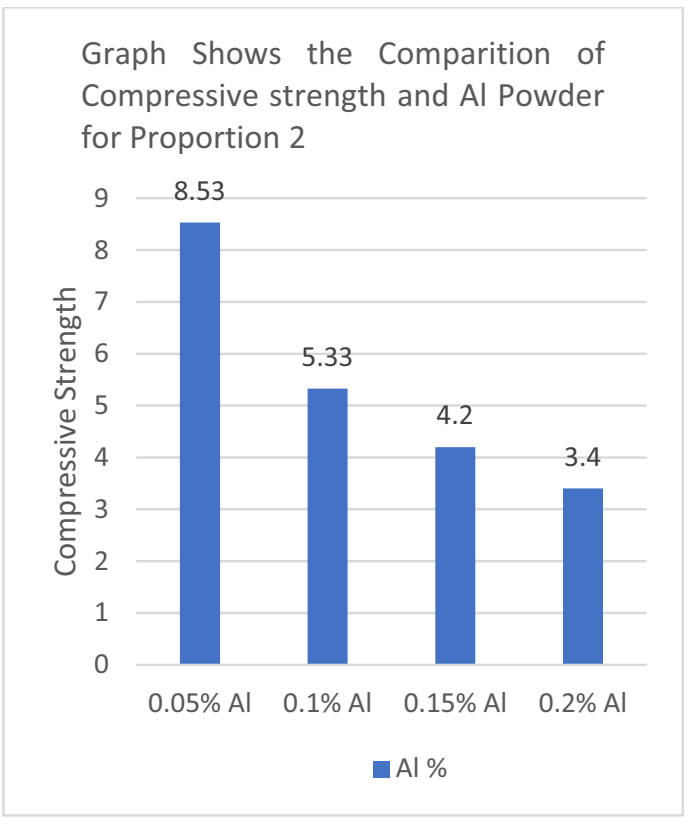

4.2 Compressive Strength of Aerated Concrete for optimum dosage of Aluminium Content for Proportion 3 
Graph Shows the Comparition of Compressive strength and Al Powder for Proportion 3

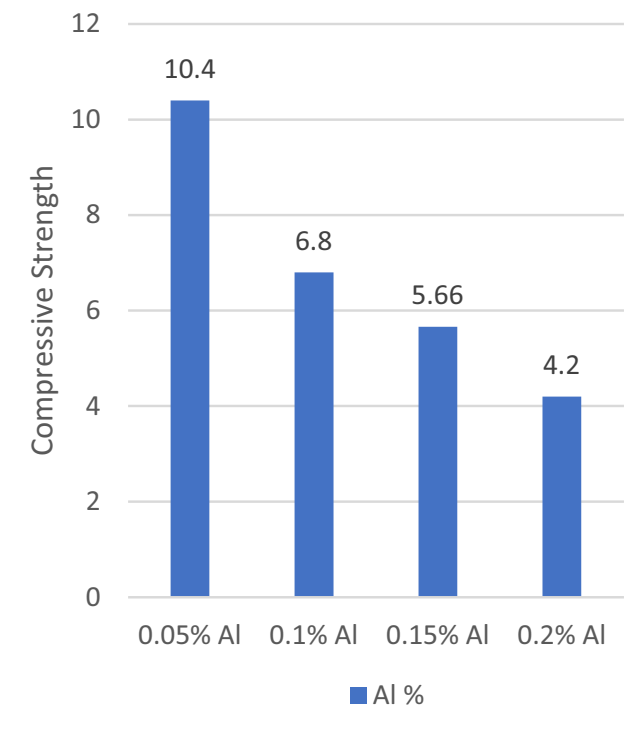

The above chart shows the maximum strength was found for $0.05 \%$ of aluminium content and it also shows that if there is increase in aerated concrete then there is decrease in strength as well.

4.3 Change in volume of Aerated Concrete for optimum dosage of Aluminium Content for proportion 2

\section{Graph Shows the Comparition of Change in volume and Al Powder for Proportion 2}

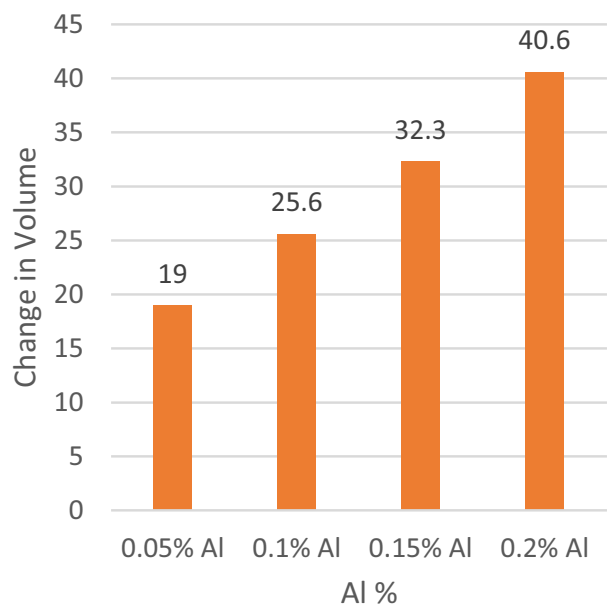

4.4 Change in volume of Aerated Concrete for optimum dosage of Aluminium Content for proportion 3
Graph Shows the Comparition of Change in volume and Al Powder for Proportion 3

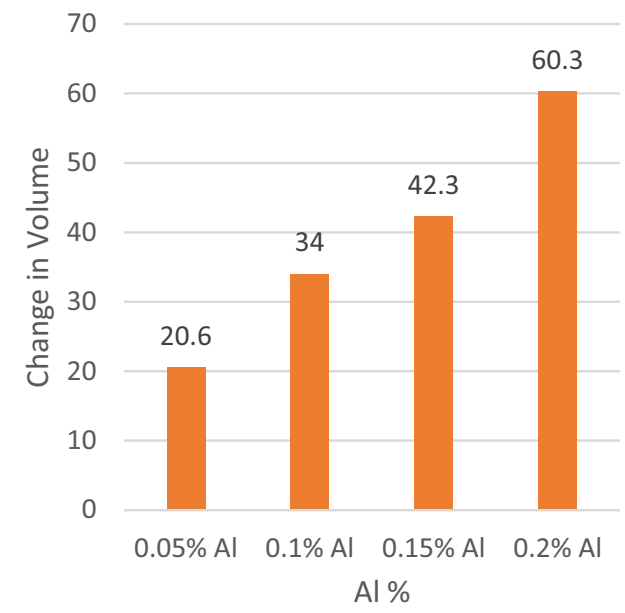

The above graph shows if there is increase in aluminium content then there is increase in volume.

4.5 Comparison of Steam Curing and water curing for proportion 2

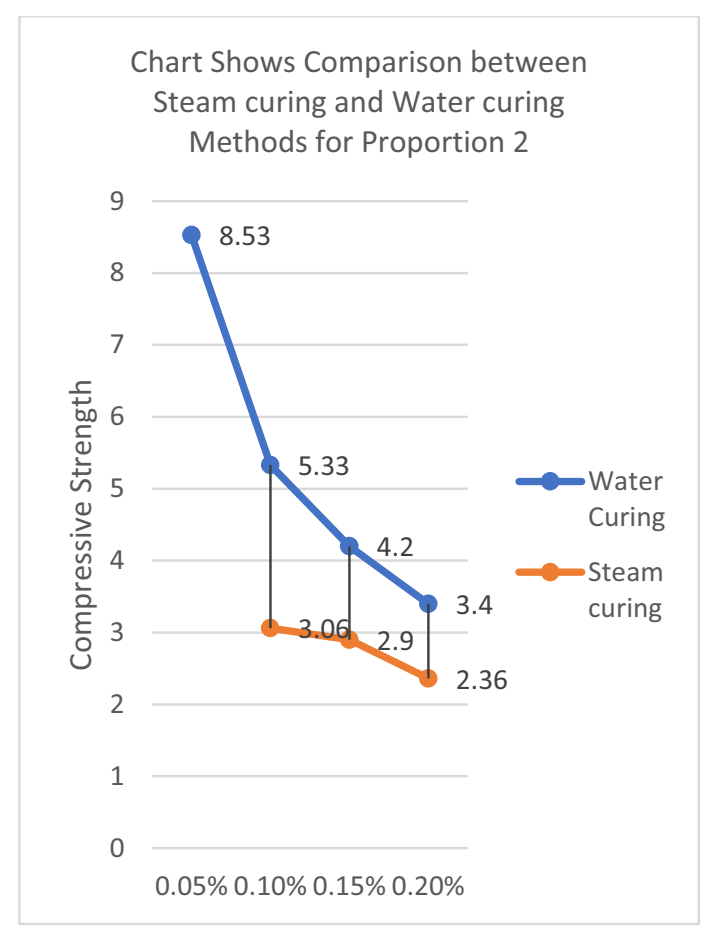

4.6 Comparison of steam curing and water curing for proportion 3 


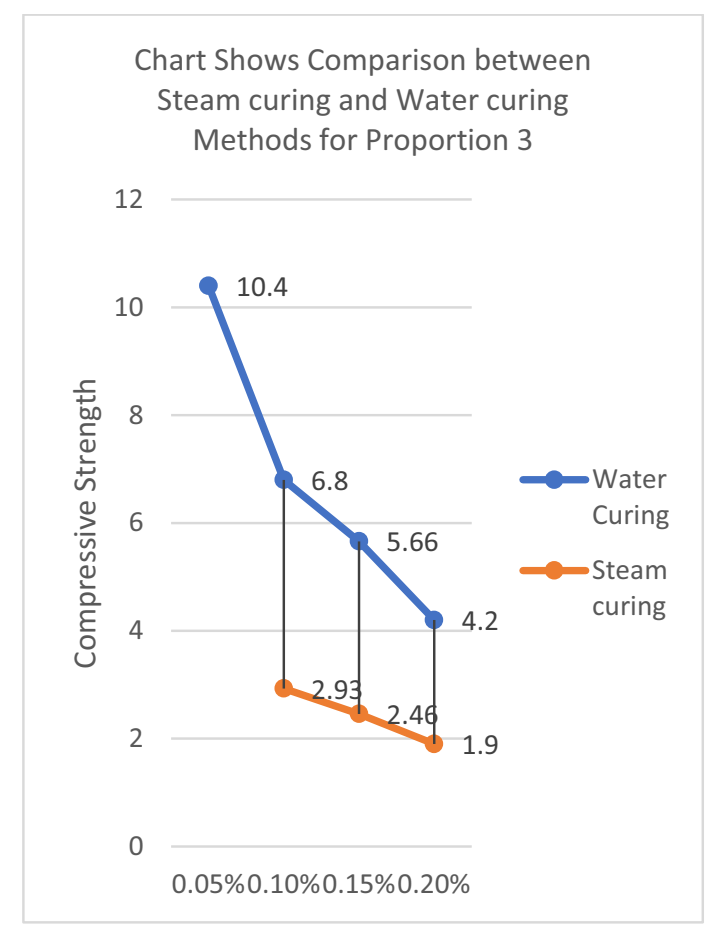

\section{Conclusion}

- Aerated concrete is generally used as a nonstructural element and aerated concrete is used as a brick replacement in high rise buildings.

- As we can see in the above chart 4.5 and 4.6 for proportion 2 and proportion 3 there is drastically change. And we can conclude that compared to proportion 2, proportion 3 gives the better result.

- From the above charts strength is inversely proportional to the aluminium powder and volume is directly proportional to aluminium powder.

- But at a certain dosage of aluminium content by using conventional curing method we can replace the brick by aerated concrete.

\section{Reference}

1. Kaliprasanna sethy, Girija sankar nayak, sushri rojalin nanda, Aerated Concrete: A Revolutionary Construction Material IJETSR, ISSN 2394-3386, Volume 5 ; issue 4, (2018).

2. Prajakta Dinesh Bulkade, Comparison of Analysis of Building with Conventional Bricks and AAC Blocks with Silicon Admixture, IJSRD Vol 5 issue 9, (2017).
3. Satish Kumar. B, Sukumar. R, Srinath, experimental analysis of aerated concrete block" international journal of engineering research and technology. ISSN: 2278-0181, vol.6 (2017).

4. Anurag Wahane, Manufacturing process of AAC blocks, International journal of innovative research in science, engineering and technology (2017).

5. Farhana M. Saiyed, Ashish H. Makwana, Jayeshkumar Pitroda, Chetna M. Vyas, "Aerated Autoclaved Concrete (AAC) Blocks: Novel Material for Construction Industry", International Journal of Advanced Research in Engineering, Science and Management, Vol. 1, Issue 2, (2014).

6. George Schober, Porosity in autoclaved aerated concrete (AAC): A review on pore structure, types of porosity, measurement methods and effects of porosity on properties, 82140 Olching, Germany, (2005) 